\title{
Measurable Krukenberg tumor is preferably characterized as a non-target lesion in the clinical evaluation of gastric cancer therapeutics: A case report
}

\author{
BI-CHENG WANG ${ }^{1 *}$, CHEN FU $^{2 *}$, JUN-LI LIU ${ }^{1}$, YU-TING LI ${ }^{1}$, TAO ZHANG ${ }^{1}$, \\ GANG WU ${ }^{1}$, QUENTIN LIU ${ }^{3,4}$ and JUN XUE ${ }^{1}$
}

\begin{abstract}
${ }^{1}$ Cancer Center, Union Hospital, Tongji Medical College, Huazhong University of Science and Technology; ${ }^{2}$ Department of Dermatology, the First Hospital of Wuhan, Wuhan, Hubei 430022; ${ }^{3}$ State Key Laboratory of Oncology in South China, Collaborative Innovation Center for Cancer Medicine, Cancer Center, Sun Yat-sen University, Guangzhou, Guangdong 510060; ${ }^{4}$ Institute of Cancer Stem Cell, Dalian Medical University, Dalian, Liaoning 116044, P.R. China
\end{abstract}

Received September 5, 2018; Accepted October 8, 2018

DOI: $10.3892 / \mathrm{mco} .2018 .1744$

\begin{abstract}
Metastatic cystic lesions may be considered as target lesions according to the Response Evaluation Criteria in Solid Tumors (RECIST) 1.1. However, cystic lesions are considered as non-measurable according to RECIST 1.0. Krukenberg tumors are cystic metastases from gastric cancer. The aim of the present case report was to address the question of whether a Krukenberg tumor can be considered as a target lesion. A 30-year-old female patient was diagnosed with stage IV gastric cancer 6 months after parturition. Subsequently, the patient received two courses of oxaliplatin/capecitabine plus trastuzumab (OCT) treatment. The response evaluation
\end{abstract}

Correspondence to: Dr Jun Xue, Cancer Center, Union Hospital, Tongji Medical College, Huazhong University of Science and Technology, 1277 Jiefang Road, Wuhan, Hubei 430022, P.R. China E-mail: xjunion@126.com

Dr Quentin Liu, State Key Laboratory of Oncology in South China, Collaborative Innovation Center for Cancer Medicine, Cancer Center, Sun Yat-sen University, 651 Dongfeng Road East, Guangzhou, Guangdong 510060, P.R. China

E-mail: liuq9@mail.sysu.edu.cn

Abbreviations: RECIST, Response Evaluation Criteria in Solid Tumors; SD, stable disease; PD, progressive disease; CAPEOX, oxaliplatin/capecitabine; OCT, oxaliplatin/capecitabine plus trastuzumab; CEA, carcinoembryonic antigen; CA19-9, cancer antigen 19-9; CA125, cancer antigen 125; CA153, cancer antigen 153; AFP, $\alpha$-fetoprotein; PSA, prostate-specific antigen; CT, computed tomography; MRI, magnetic resonance imaging; PET/CT, positron emission tomography-computed tomography

\section{${ }^{*}$ Contributed equally}

Key words: gastric cancer, target lesion, Krukenberg tumor, therapeutic assessment, Response Evaluation Criteria in Solid Tumors was considered as stable disease. However, after four courses of OCT, the cystic target lesion in the right pelvic cavity exhibited an increase in diameter of $>40 \%$. After one more cycle of OCT, contrast-enhanced magnetic resonance imaging (MRI) revealed that the diameter of the cystic mass lesion had decreased by $>35 \%$ and a further two cycles of treatment were administered. After the last OCT cycle, the levels of the tumor markers cancer antigen (CA) 125, CA19-9 and CA153 had markedly increased, although the cystic mass had decreased in size. Eventually, positron emission tomography-computed tomography (PET/CT) was used to assess the efficacy of treatment. A new lesion was identified, indicating progressive disease. The present case demonstrated that the Krukenberg tumor may be considered as a non-target lesion. In addition, tumor markers and PET/CT yielded results complementary to those of contrast-enhanced MRI in the therapeutic assessment of advanced gastric cancer.

\section{Introduction}

Gastric cancer is the fourth most common malignant tumor worldwide (1) and the second most common malignant tumor in China (2). Although the overall incidence of gastric cancer has been decreasing over the last two decades (3), the 5 -year mortality rate for advanced gastric cancer remains $30-50 \%$ (4).

A proportion of advanced gastric cancer patients are diagnosed with Krukenberg tumors. Krukenberg tumors are metastatic ovarian tumors arising from a specific type of gastric cancer (signet-ring cell carcinoma). The median overall survival of advanced gastric cancer has been reported to be 13-19.2 months (5-9). These patients may not be considered eligible for surgical resection, and are instead treated with chemotherapy or local radiotherapy. After every 2-4 cycles of chemotherapy, tumor re-evaluation is performed. At baseline at the time of diagnosis and during follow-up, tumor lesions (such as liver and lung metastatic nodules) and positive lymph nodes ( $\geq 15 \mathrm{~mm}$ in the short axis) may be selected as target lesions. Under certain conditions, if only metastatic cystic 

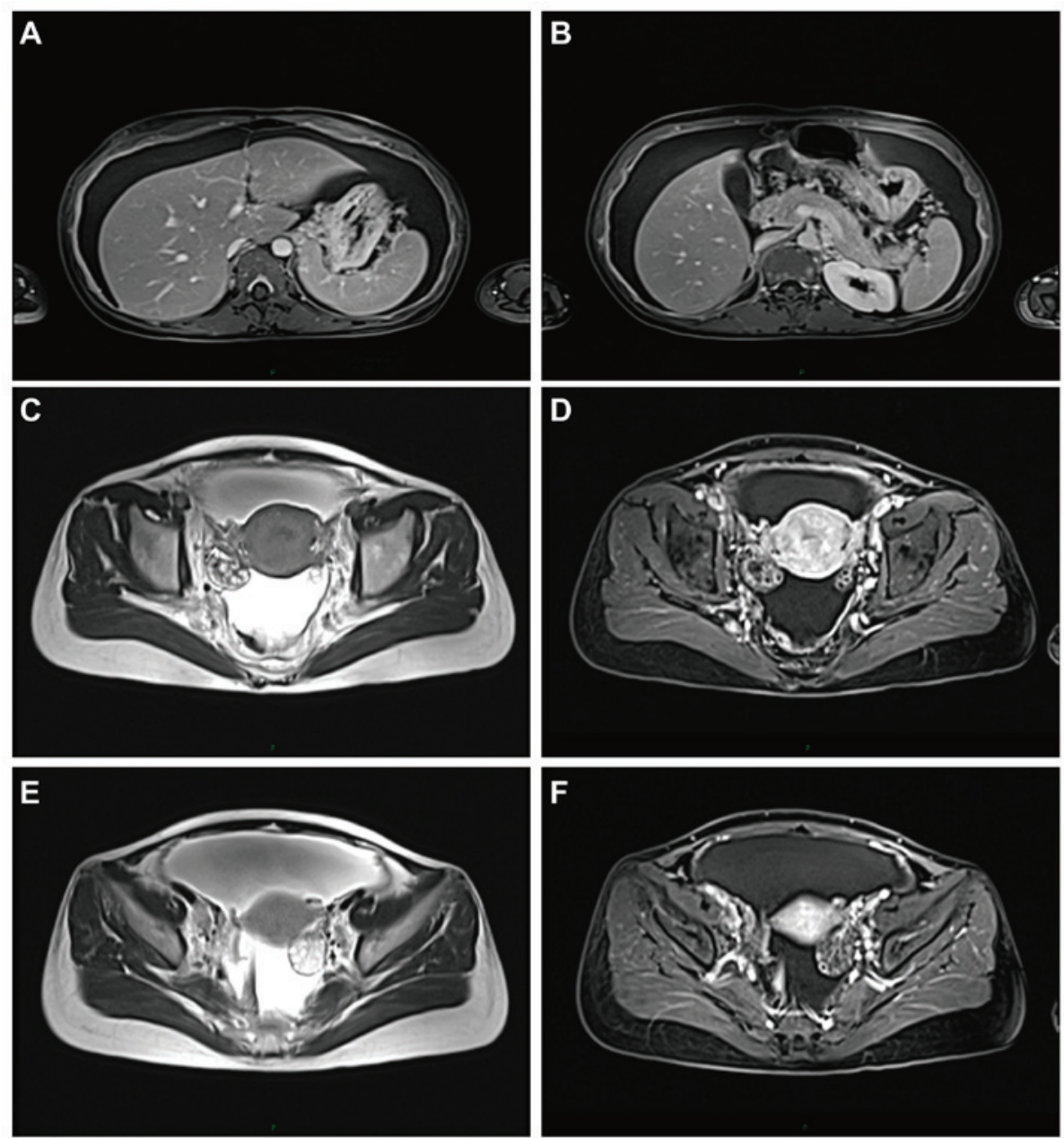

Figure 1. Abdominal and pelvic contrast-enhanced magnetic resonance imaging (MRI) at baseline at the time of diagnosis. (A and B) Contrast-enhanced MRI revealed massive ascites and thickened gastric wall (linitis plastica); (C-F) two cystic lesions located in the pelvic cavity were identified on T2-weighted contrast-enhanced images.

lesions are present in the patient, these measurable cystic masses may be considered as target lesions (10).

We herein report a case of gastric cancer complicated by a Krukenberg tumor. The question of whether the Krukenberg tumor could be considered as the target lesion in the therapeutic assessment of gastric cancer was addressed. Although the measurable cystic lesion decreased by $>30 \%$ in greatest diameter after a course of chemotherapy, the increasing levels of tumor markers and a new lesion detected on positron emission tomography-computed tomography (PET/CT) indicated progressive disease.

\section{Case report}

A 30-year-old woman without a relevant medical or significant family history visited a local hospital in May 2017 due to abdominal distention, nausea and melena; the symptoms reportedly increased after eating. The patient underwent gastroscopy, which revealed a thickened gastric wall (linitis plastica), with several hard and bleeding ulcers. The patient was histologically diagnosed with adenocarcinoma of the gastric fundus. Human epidermal growth factor receptor 2 immunostaining was performed and scored as $3+$. Abdominal $\mathrm{CT}$ and ultrasonography were performed and revealed massive ascites and thickening of the peritoneum. The patient underwent diagnostic abdominocentesis, and routine ascites cytology analysis indicated malignancy. During June 2018, the patient was transferred to the Cancer Center, Union Hospital, Tongji Medical College, Huazhong University of Science and Technology (Wuhan, China) for more thorough examination. The pathological consultation reported a poorly differentiated adenocarcinoma of the gastric fundus, which was proven to be signet-ring cell carcinoma. Abdominal and pelvic contrastenhanced magnetic resonance imaging (MRI) revealed gastric adenocarcinoma with mesenteric, greater omental, peritoneal and pelvic metastases, and a cystic mass $(3.2 \times 2.2 \mathrm{~cm})$ to the right of the uterus, which was considered to be a Krukenberg tumor (Fig. 1). A bone scan revealed enhancement in the ribs, thoracic vertebrae, lumbar vertebrae and left and right iliac crests. As regards tumor markers, the carcinoembryonic antigen (CEA; $67.27 \mu \mathrm{g} / \mathrm{ml}$; normal value: $<5 \mu \mathrm{g} / \mathrm{ml}$ ), cancer antigen (CA)19-9 (3,073.9 U/ml; normal value: $<37 \mathrm{U} / \mathrm{ml})$ and CA125 (301.6 U/ml; normal value: $<35 \mathrm{U} / \mathrm{ml}$ ) levels were raised, while the $\alpha$-fetoprotein (AFP; $3.8 \mu \mathrm{g} / \mathrm{l}$; normal value: 0.89 $8.78 \mu \mathrm{g} / \mathrm{l})$ and CA15-3 (16.8 U/ml; normal value: $<31.3 \mathrm{U} / \mathrm{ml})$ levels were normal. According the TNM Classification of Malignant Tumors classification (11), the final diagnosis was poorly differentiated gastric adenocarcinoma, stage IV. 

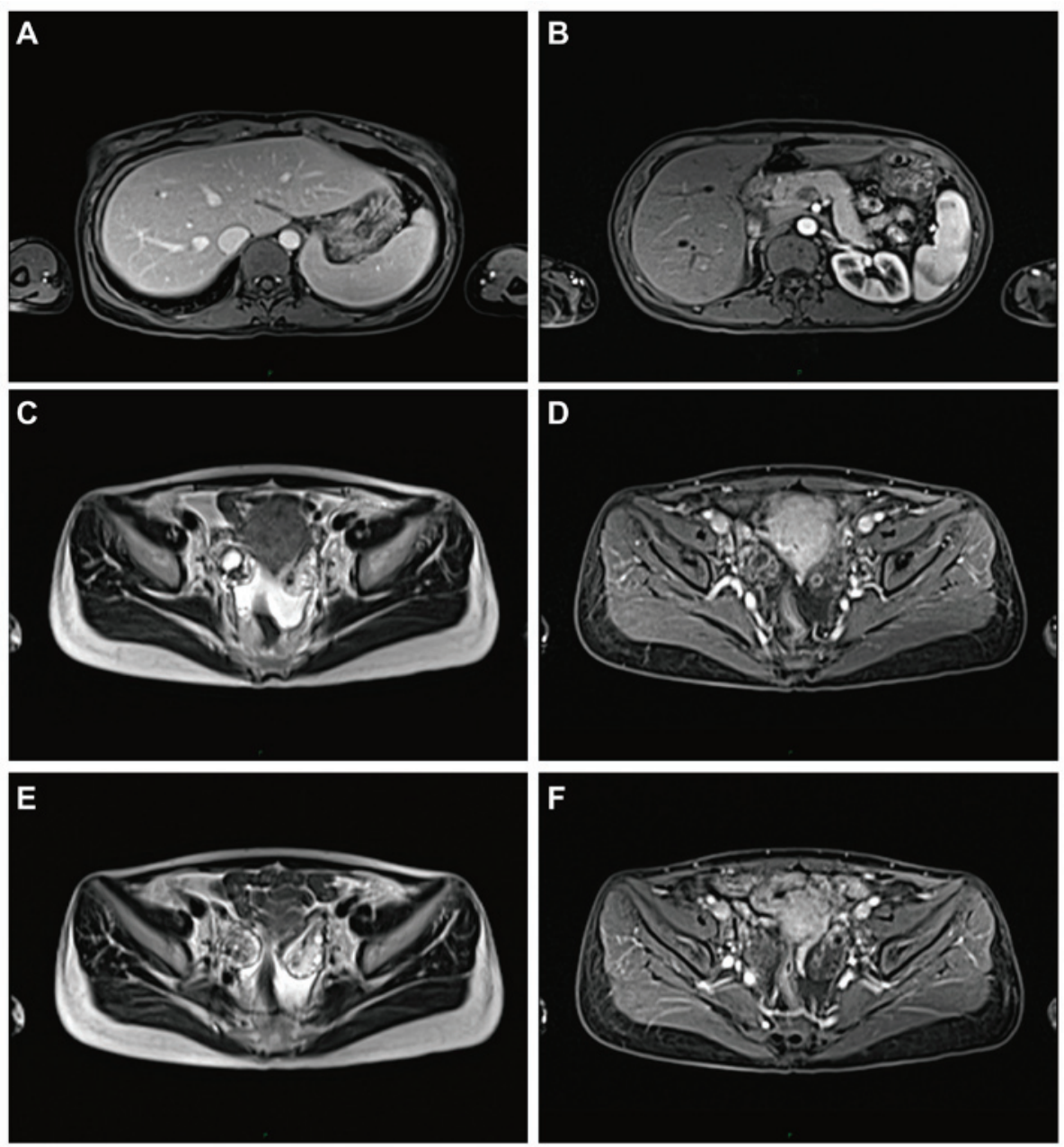

Figure 2. Abdominal and pelvic contrast-enhanced magnetic resonance imaging (MRI) after two courses of OCT treatment. (A and B) Contrast-enhanced MRI revealed mild ascites and reduced thickness of the gastric wall; (C-F) the cystic lesions are shown on T2-weighted and contrast-enhanced images after two courses of OCT treatment. OCT, oxaliplatin/capecitabine plus trastuzumab.

Due to the multiple metastases, the patient was not considered to be an eligible candidate for surgery. In total, she received seven courses of oxaliplatin/capecitabine [oxaliplatin, $130 \mathrm{mg} / \mathrm{m}^{2}$ (day 1); capecitabine, $1,000 \mathrm{mg} / \mathrm{m}^{2}$ (days 1-14)] plus trastuzumab (OCT) chemotherapy [oxaliplatin $130 \mathrm{mg} / \mathrm{m}^{2}$ (day 1); capecitabine $1,000 \mathrm{mg} / \mathrm{m}^{2}$ (days 1-14); and trastuzumab $8 \mathrm{mg} / \mathrm{m}^{2}$ (day 0 prior to treatment initiation, first course of 21 days) and $6 \mathrm{mg} / \mathrm{m} 2$ (day 0, 2-7 courses, 21 days/course)]. After two courses, the therapeutic assessment was stable disease (Fig. 2). The patient's serum CEA, CA19-9 and CA125 levels had decreased to $3.00 \mu \mathrm{g} / \mathrm{ml}$, $61.1 \mathrm{U} / \mathrm{ml}$ and $17.9 \mathrm{U} / \mathrm{ml}$, respectively, after three courses of chemotherapy. However, after four courses of OCT, the CEA, CA19-9 and CA125 levels mildly increased. Abdominal and pelvic contrast-enhanced MRI revealed that the size of the right adnexal cystic mass had increased to $4.6 \times 3.9 \mathrm{~cm}$, a $43.13 \%$ increase compared with the baseline at diagnosis (Fig. 3A and B). Considering that the patient experienced monthly menstrual cycles, although the diameter of the Krukenberg tumor was increased, the treatment efficacy was difficult to assess. Therefore, OCT treatment was continued. Abdominal and pelvic contrast-enhanced MRI examination revealed that the cystic mass $(1.4 \mathrm{cx} 2.9 \mathrm{~cm}) \mathrm{had}$ decreased in size by $36.96 \%$ compared with after the last course (Fig. 3C and D). However, the serum CEA, CA19-9 and CA125 levels had markedly increased to $14.80 \mu \mathrm{g} / \mathrm{ml}$, $1,179.4 \mathrm{U} / \mathrm{ml}$ and $38.7 \mathrm{U} / \mathrm{ml}$, respectively. At this point, the patient's Eastern Cooperative Oncology Group performance status score was 0 , and there was no evidence supporting a change in the treatment regimen. As the cystic mass had decreased in size, the patient was administered two more courses of OCT chemotherapy. Unexpectedly, the serum CEA, CA19-9 and CA125 levels increased rapidly to $65.7 \mu \mathrm{g} / \mathrm{ml}, 6,081.4 \mathrm{U} / \mathrm{ml}$ and $104.7 \mathrm{U} / \mathrm{ml}$, respectively, after the seventh cycle (Fig. 4). At this point, the patient remained in good condition, without abdominal or pelvic pain, bloating or abdominal distension, but reported changes in the menstrual cycle and vaginal bleeding. Moreover, the $\beta$-human chorionic gonadotropin level was $7.3 \mathrm{mIU} / \mathrm{ml}$ (normal value: $<5 \mathrm{mIU} / \mathrm{ml}$ ). Whole-body PET/CT was then performed, revealing increased ${ }^{18} \mathrm{~F}$-fluorodeoxyglucose (FDG) uptake in the gastric fundus and body, left adrenal gland, mesentery and right pelvic cystic mass, with maximum standardized uptake values of 4.3-13.0, 4.5, 2.1-2.6 and 1.6-2.7, respectively (Fig. 5). As a new lesion was found in the left adrenal gland, the final response evaluation of the patient was progressive disease and docetaxel monotherapy $\left(60 \mathrm{mg} / \mathrm{m}^{2}\right.$ on day 1 every three weeks) was initiated as second-line treatment (Fig. 6). 

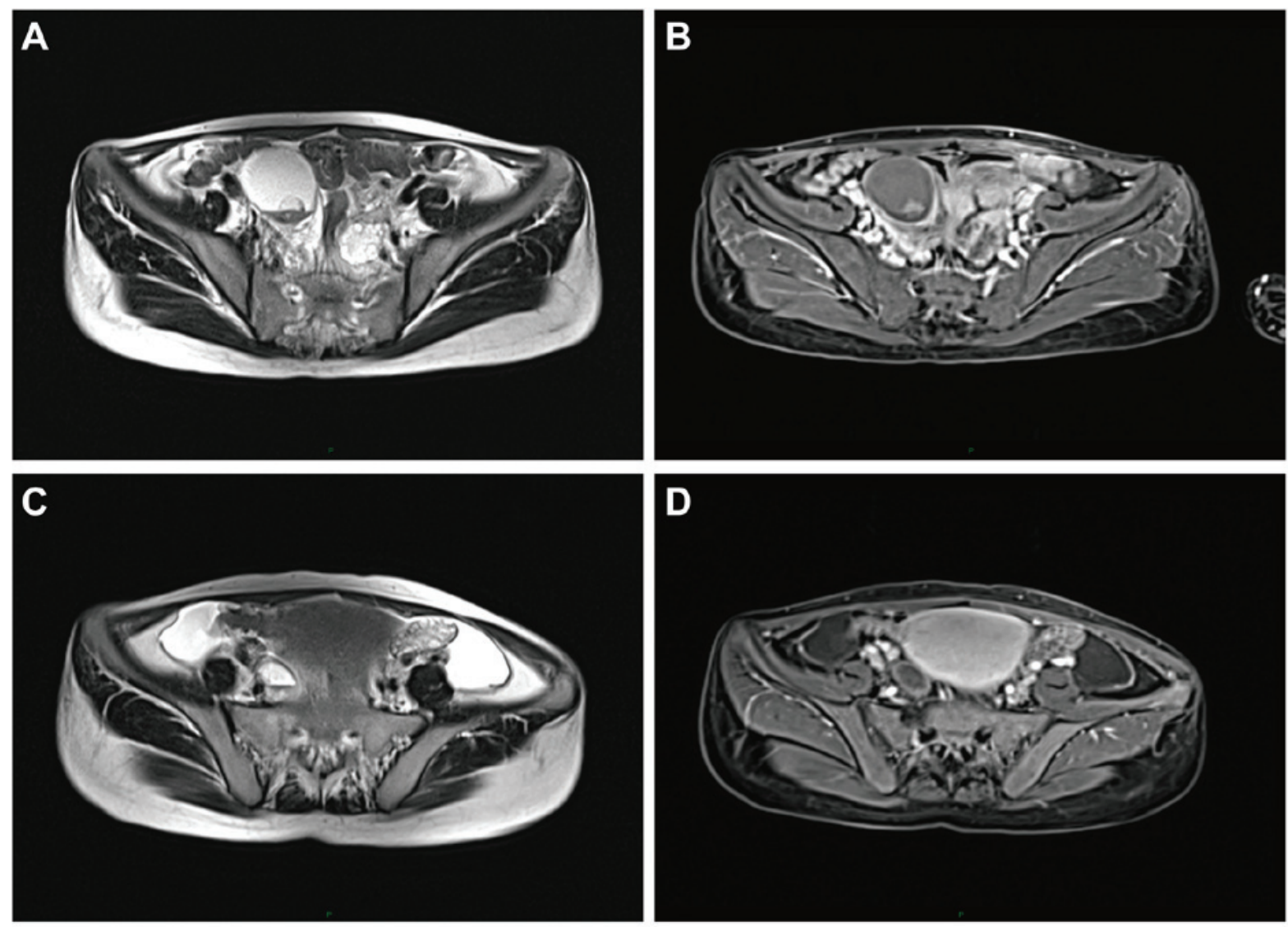

Figure 3. Abdominal and pelvic contrast-enhanced magnetic resonance imaging (MRI) after (A and B) four courses and (C and D) five courses of OCT treatment. OCT, oxaliplatin/capecitabine plus trastuzumab.
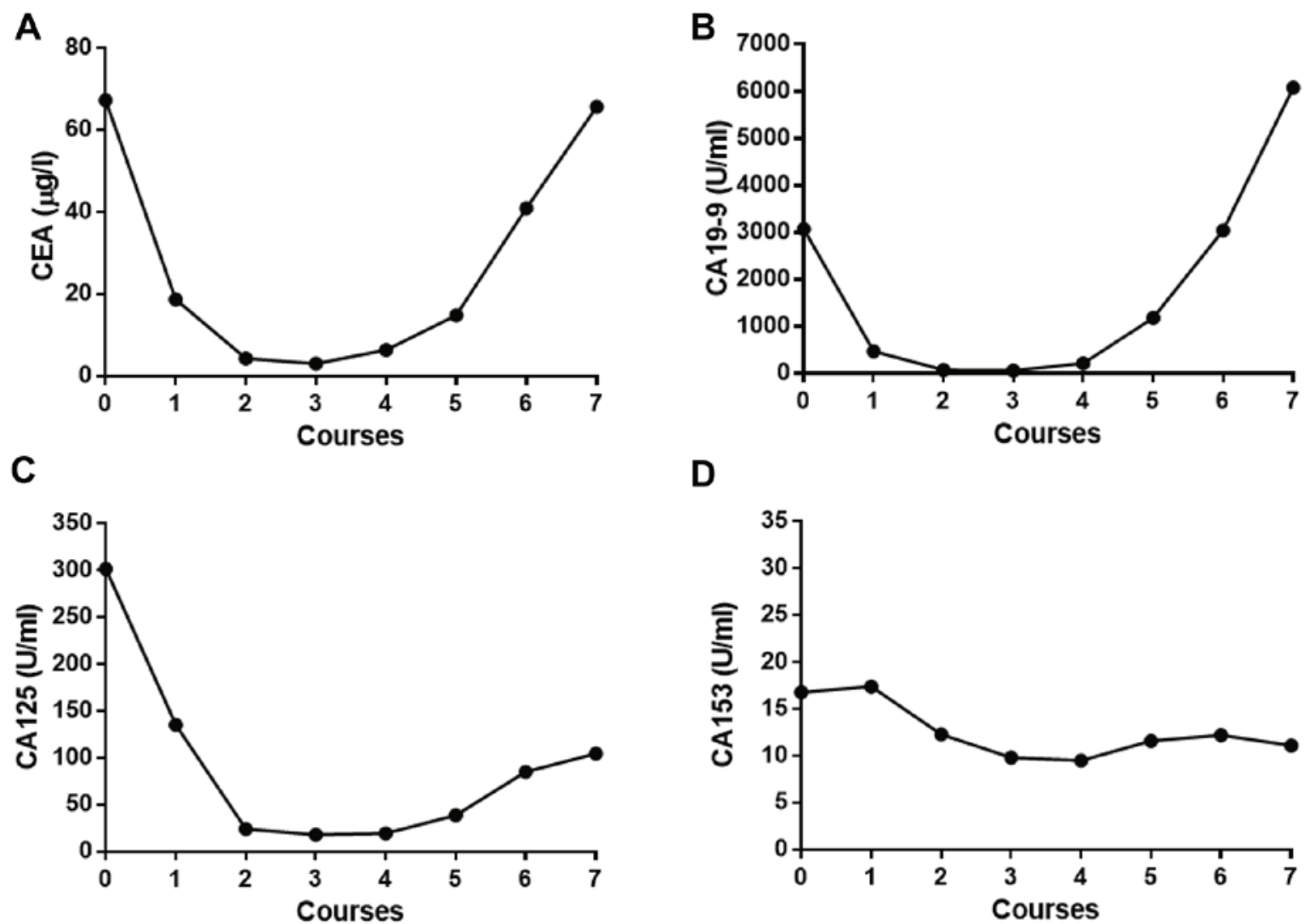

Figure 4. Expression levels of tumor markers after OCT therapy, including (A) CEA, (B) CA19-9, (C) CA125 and (D) CA153. OCT, oxaliplatin/capecitabine plus trastuzumab; CEA, carcinoembryonic antigen; CA, cancer antigen. 

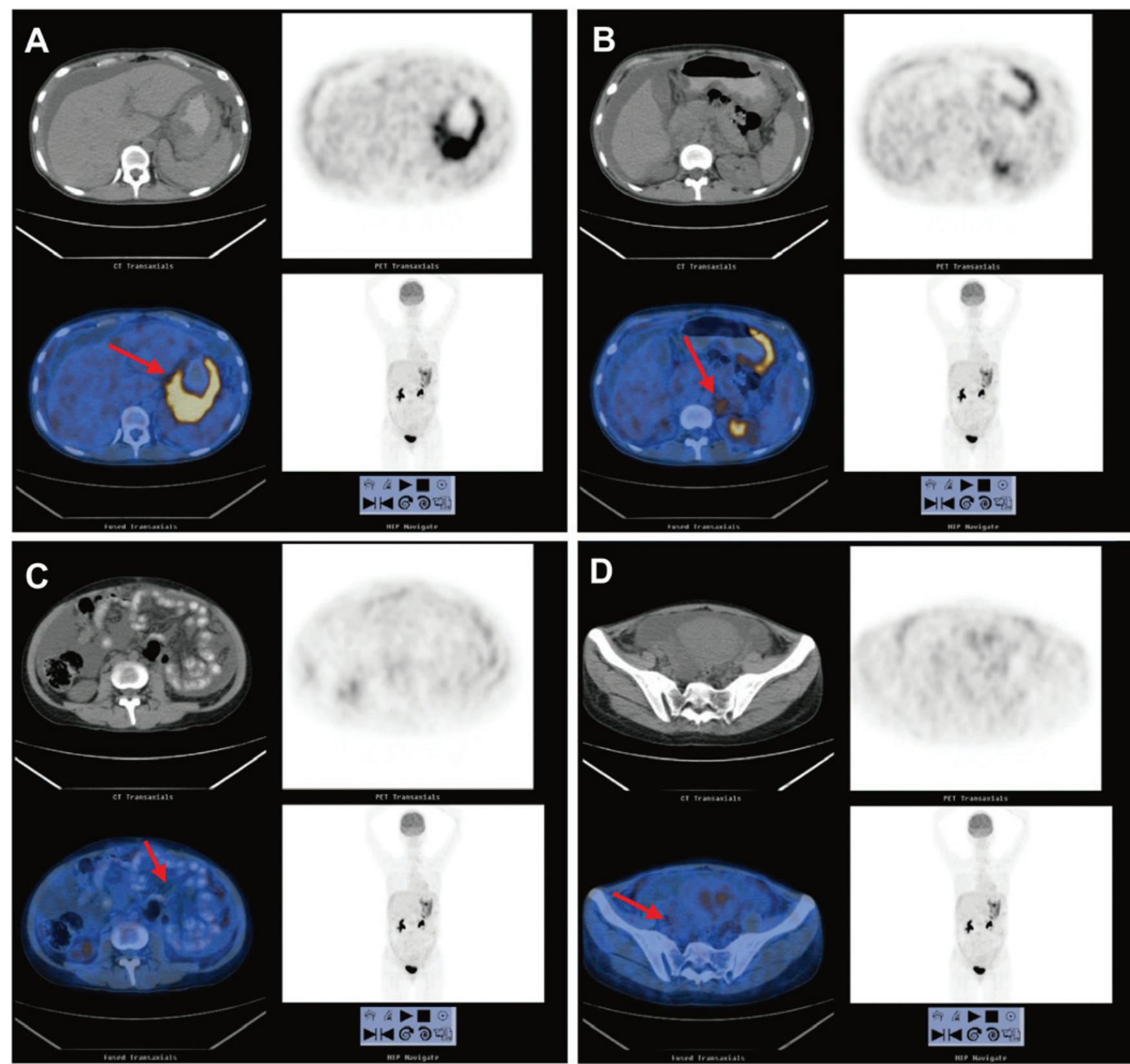

Figure 5. Positron emission tomography-computed tomography (PET-CT). A whole-body PET-CT scan revealed fluorodeoxyglucose uptake in the (A) gastric fundus and body, (B) left adrenal gland, (C) mesentery and (D) a right pelvic cystic mass.

\begin{tabular}{|c|c|c|c|}
\hline $\begin{array}{c}\text { CAPEOX } \\
+ \\
\text { Trastuzumab } \\
\times 2\end{array}$ & $\begin{array}{c}\text { CAPEOX } \\
+ \\
\begin{array}{c}\text { Trastuzumab } \\
\times 2\end{array}\end{array}$ & $\begin{array}{c}\text { CAPEOX } \\
+ \\
\text { Trastuzumab } \\
\times 1\end{array}$ & $\begin{array}{c}\text { Trastuzumab } \\
\times 2\end{array}$ \\
\hline
\end{tabular}

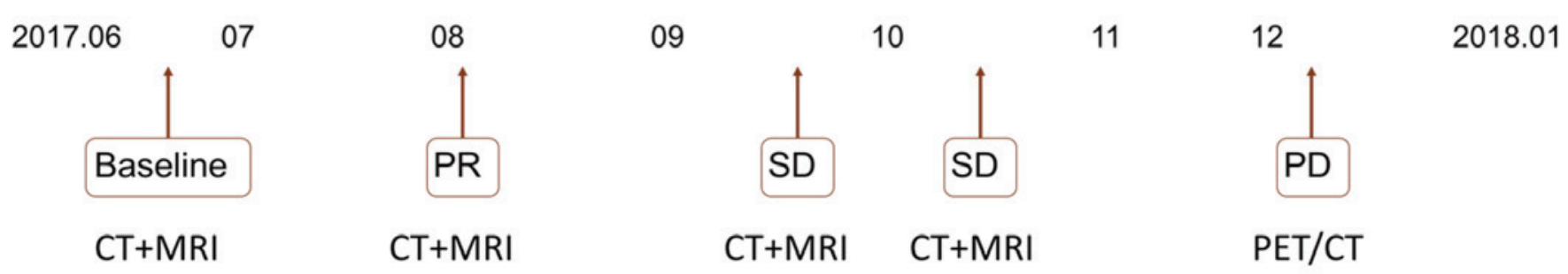

Figure 6. Schematic illustration of the treatment course. CT, computed tomography; MRI, contrast-enhanced magnetic resonance imaging; PET/CT, positron emission tomographycomputed tomography; PR, partial response; SD, stable disease; PD, progressive disease; CAPEOX, capecitabine plus oxaliplatin. 


\section{Discussion}

Krukenberg tumors are defined as ovarian metastatic tumors, two-thirds of which originate from the stomach (12). On imaging, these tumors may appear as well-demarcated intramural cysts $(12,13)$. MRI shows a hypointense signal density of the solid components on T2-weighted images (14-16). According to RECIST 1.0 (17), cystic lesions are considered to be non-target lesions. In the present study, based on the persistence of the non-target lesions (including Krukenberg tumors) and the levels of the tumor markers being persistently raised over the normal limits, the therapeutic assessment of the patient after four and five cycles of treatment was incomplete response/ stable disease. However, according to RECIST 1.1 (10), if only cystic measurable lesions are present in the same patient, they may be considered as target lesions. Therefore, after four courses of OCT, the patient should have been considered to have progressive disease, whereas the therapeutic assessment was partial response after five courses of OCT treatment, although the levels of the tumor markers had markedly increased. These assessments were contradictory. If treatment had failed, partial response would not have been achieved after another cycle of OCT treatment. After seven courses of OCT, PET/CT revealed progression. It was then hypothesized that the patient may have already been progressive after four cycles of OCT.

In the present case report, it appears more appropriate to adopt RECIST 1.0 rather than the 1.1 version. Cystic lesions, such as Krukenberg tumors, are preferably considered as non-target lesions. In 2004, Husband et al (18) suggested that characterizing all cystic lesions as targets, which may still be included in the assessment and documentation of the changes in tumor composition, should be avoided. Over the last two decades, there have only been few studies on the evaluation of cystic lesions. In the present study, we demonstrated that cystic lesions should be considered as non-target lesions, although they may be measurable.

In patients with non-measurable as well as non-target disease only, tumor marker levels should be considered in the therapeutic assessment. In both versions of RECIST, tumor markers alone cannot be used to evaluate objective tumor response. However, specific guidelines for tumor markers, including CA-125 and prostate-specific antigen, are being validated, and CA-125 is recommended for integration with objective assessment in ovarian cancer (19-22). Moreover, PET/CT may be introduced for the assessment of progression (particularly possible new lesions) (10). In this case, PET/CT was used to detect new lesions, as the tumor markers had increased multifold.

In conclusion, the present case report demonstrated that, considering measurable Krukenberg tumors or cystic lesions as target lesions in the response assessment of advanced gastric cancer, must be avoided. In addition, tumor markers and PET/CT may provide complementary results to the therapeutic assessment of advanced gastric cancer with only non-target lesions.

\section{Acknowledgements}

The authors would like to thank the members of the Xin Li team for their critical comments and technical support.

\section{Funding}

No funding was received.

\section{Availability of data and materials}

Not applicable.

\section{Authors' contributions}

BW, CF, TZ, GW and QL contributed to the conception and design of the study. BW, CF, JL, YL and JX contributed to data acquisition and analysis, and drafting of the article. TZ, GW and QL revised the manuscript. All authors have read and approved the final version for publication.

\section{Ethics approval and consent to participate}

Not applicable.

\section{Patient consent for publication}

Written informed consent was obtained from the patient and her husband for publication of this case report and any accompanying images.

\section{Competing interests}

The authors declare that they have no competing interests.

\section{References}

1. Siegel R, Naishadham D and Jemal A: Cancer statistics, 2013. CA Cancer J Clin 63: 11-30, 2013.

2. Chen W, Zheng R, Baade PD, Zhang S, Zeng H, Bray F, Jemal A. Yu XQ and He J: Cancer statistics in China, 2015. CA Cancer J Clin 66: 115-132, 2016.

3. Ferlay J, Shin HR, Bray F, Forman D, Mathers C and Parkin DM: Estimates of worldwide burden of cancer in 2008: GLOBOCAN 2008. Int J Cancer 127: 2893-2917, 2010.

4. Hamashima C, Shabana M, Okada K, Okamoto M and Osaki Y: Mortality reduction from gastric cancer by endoscopic and radiographic screening. Cancer Sci 106: 1744-1749, 2015.

5. Jeung YJ, Ok HJ, Kim WG, Kim SH and Lee TH: Krukenberg tumors of gastric origin versus colorectal origin. Obstet Gynecol Sci 58: 32-39, 2015.

6. Jiang R, Tang J, Cheng X and Zang RY: Surgical treatment for patients with different origins of Krukenberg tumors: Outcomes and prognostic factors. Eur J Surg Oncol 35: 92-97, 2009.

7. Kim HK, Heo DS, Bang YJ and Kim NK: Prognostic factors of Krukenberg's tumor. Gynecol Oncol 82: 105-109, 2001.

8. Ayhan A, Guvenal T, Salman MC, Ozyuncu O, Sakinci M and Basaran M: The role of cytoreductive surgery in nongenital cancers metastatic to the ovaries. Gynecol Oncol 98: 235-241, 2005.

9. Gagnon Y and Têtu B: Ovarian metastases of breast carcinoma. A clinicopathologic study of 59 cases. Cancer 64: 892-898, 1989.

10. Eisenhauer EA, Therasse P, Bogaerts J, Schwartz LH, Sargent D, Ford R, Dancey J, Arbuck S, Gwyther S, Mooney M, et al: New response evaluation criteria in solid tumours: Revised RECIST guideline (version 1.1). Eur J Cancer 45: 228-247, 2009.

11. Ajani JA, D'Amico TA, Almhanna K, Bentrem DJ, Chao J, Das P, Denlinger CS, Fanta P, Farjah F, Fuchs CS, et al: Gastric Cancer, Version 3.2016, NCCN Clinical Practice Guidelines in Oncology. J Natl Compr Canc Netw 14: 1286-1312, 2016.

12. Kiyokawa T, Young RH and Scully RE: Krukenberg tumors of the ovary: A clinicopathologic analysis of 120 cases with emphasis on their variable pathologic manifestations. Am J Surg Pathol 30: 277-299, 2006. 
13. Agnes A, Biondi A, Ricci R, Gallotta V, D'Ugo D and Persiani R: Krukenberg tumors: Seed, route and soil. Surg Oncol 26: 438-445, 2017.

14. Ha HK, Baek SY, Kim SH, Kim HH, Chung EC and Yeon KM: Krukenberg's tumor of the ovary: MR imaging features. AJR Am J Roentgenol 164: 1435-1439, 1995.

15. Cho JY, Seong CK and Kim SH: Krukenberg tumor findings at color and power Doppler US; correlation with findings at CT, MR imaging, and pathology. Case reports. Acta Radiol 39: 327-329, 1998.

16. Koyama T, Mikami Y, Saga T, Tamai K and Togashi K Secondary ovarian tumors: Spectrum of CT and MR features with pathologic correlation. Abdom Imaging 32: 784-795, 2007.

17. Therasse P, Arbuck SG, Eisenhauer EA, Wanders J, Kaplan RS, Rubinstein L, Verweij J, Van Glabbeke M, van Oosterom AT, Christian MC, et al: New guidelines to evaluate the response to treatment in solid tumors. European Organization for Research and Treatment of Cancer, National Cancer Institute of the United States, National Cancer Institute of Canada. J Natl Cancer Inst 92: 205-216, 2000.

18. Husband JE, Schwartz LH, Spencer J, Ollivier L, King DM, Johnson R and Reznek R; International Cancer Imaging Society: Evaluation of the response to treatment of solid tumours - a consensus statement of the International Cancer Imaging Society. Br J Cancer 90: 2256-2260, 2004

19. Vergote I, Rustin GJ, Eisenhauer EA, Kristensen GB Pujade-Lauraine E, Parmar MK, Friedlander M, Jakobsen A and Vermorken JB: Re: New guidelines to evaluate the response to treatment in solid tumors [ovarian cancer]. Gynecologic Cancer Intergroup. J Natl Cancer Inst 92: 1534-1535, 2000.
20. Rustin GJ, Quinn M, Thigpen T, du Bois A, Pujade-Lauraine E, Jakobsen A, Eisenhauer E, Sagae S, Greven K, Vergote I, et al: Re: New guidelines to evaluate the response to treatment in solid tumors (ovarian cancer). J Natl Cancer Inst 96: 487-488, 2004.

21. Bubley GJ, Carducci M, Dahut W, Dawson N, Daliani D Eisenberger M, Figg WD, Freidlin B, Halabi S, Hudes G, et al: Eligibility and response guidelines for phase II clinical trials in androgen-independent prostate cancer: Recommendations from the Prostate-Specific Antigen Working Group. J Clin Oncol 17: 3461-3467, 1999.

22. Scher HI, Halabi S, Tannock I, Morris M, Sternberg CN, Carducci MA, Eisenberger MA, Higano C, Bubley GJ, Dreicer R, et al; Prostate Cancer Clinical Trials Working Group: Design and end points of clinical trials for patients with progressive prostate cancer and castrate levels of testosterone: Recommendations of the Prostate Cancer Clinical Trials Working Group. J Clin Oncol 26: 1148-1159, 2008.

This work is licensed under a Creative Commons Attribution-NonCommercial-NoDerivatives 4.0 International (CC BY-NC-ND 4.0) License. 